\title{
加硫 $\mathrm{SBR}, \mathrm{BR}$ の大変形挙動
}

$$
\begin{aligned}
& \text { 桜 井正 幸** 佐 藤 良 泰*** }
\end{aligned}
$$

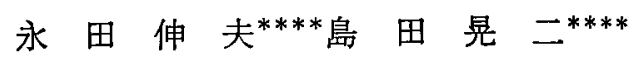

\section{Large Elastic Behavior of SBR and BR Vulcanizates}

\author{
by \\ Masayuki SAKURAI and Yoshiyasu Sato \\ (Faculty of Textile Science and Technology, Shinshu University, Ueda) \\ Nobuo Nagata and Kouji Shrmada \\ (Japan Geon Co., Ltd., Central Research Laboratory, Kawasaki)
}

In the preceding paper ${ }^{12}$, a report was made of the study enactted by one of the authors of the stress-strain relation that was obtained from the phenomenological theory of finite deformation. So far as the incompressible materials were concerned, the relation was written as follows:

$$
f=\left(A+B / \alpha+C \alpha^{2}\right)\left(\alpha-1 / \alpha^{2}\right)
$$

where $f$ denoted the tension at extension ratio $\alpha, A, B$, and $C$ were constants.

In this paper, the applicability of the Eq. (1) to the stress-strain behavior of styrene-butadiene rubber ( $\mathrm{SBR}$ ) and butadiene rubber (BR) was tested, and the temperature dependences of the values of $A, B, C$ were examined. This is, however, only a preliminary examination, because the data discussed in this paper were determined while making the study of fracture phenomena, and little attention was paid to attaining equilibrium state in obtaining the data.

SBR and BR were both cured with tetramethyl thiuram disulfide and contained 5 parts of zinc oxide and 2 parts of stearic acid per 100 parts of rubber. The stress-strain data were determined by means of an Instron type tester at various temperatures between -40 and $120^{\circ} \mathrm{C}$ at a crosshead speed $50 \mathrm{~mm} / \mathrm{min}$.

It was found that at temperature over $30^{\circ} \mathrm{C}$, fracture occurred at low extensions $(\alpha>3)$ and Mooney-Rivlin equation (Same tipe equation as Eq. (1) where $C=0$ ) was in agreement with the data over $30^{\circ} \mathrm{C}$, and that at temperatures below $30^{\circ} \mathrm{C}$, the experimental stress-strsin relations almost coincided with the relation of Eq. (1) in the extension range $\alpha<4.5$, while Mooney-Rivlin equation coincided with the data only in the extension range $\alpha<3$. It was found also that the values of $A$ for SBR and BR showed almost linear increase with temperature above $30^{\circ} \mathrm{C}$, the values of $B$ and $C$ decreased with increase of temperature and $C$ were almost 0 for the data above $30^{\circ} \mathrm{C}$.

(Received Jan. 5, 1970)

\section{1 まえがき}

単純伸長に括ける Mooney-Rivlin の張力-伸度の式 は, Treloar らによると, 理論的には, $I_{1}, I_{2}, I_{3}$ を 伸度の不変量として, エネルギ関数 $w\left(I_{1}, I_{2}, I_{3}\right)$ の Taylor 屡開における $I_{1}, I_{2}, I_{3}$ についての第 1 近似 式から導かれるとされている.著者の 1 人はその第 1 近似のとり方に疑問をむち，正確な近似から導か机る 張力-伸度の式は

$$
f=\left(A+\frac{B}{\alpha}+c \alpha^{2}\right)\left(\alpha-\frac{1}{\alpha^{2}}\right)
$$

ではないかと提唱しだ2 上式で $f$ は変形前の単位断面 積当たりの張力， $\alpha$ は伸度， $A, B, C$ は定数を表わ す. この式を導く取り扱いは現象論であるから、ジム 状弾性の分子論が主としてェントロピー弾性をあつか つているのに対し，エネルキ弾性も総合されている. その反面定数 $A, B, C$ の分子論的意味は不明である. そこで，最初汇(1)式がゴム状物質の大変形挙動をど の程度近似できるかを，2種類の合成ゴムの測定デー タについて検討した。湘定データは，特にこの研究の ために得られたものではないため非平衡の粗いデータ である.つぎに，定数 $A, B, C$ の分子諭的意味の大 略を推定するため, それら定数の温度倲存性を検討し た。 


\section{2 実}

験

\section{$2 \cdot 1$ 試料}

試料としてスチレンーブタシェンゴム(SBR 1500), ブタジェンゴム（BR 1441）の 2 種類を用いた。 SBR

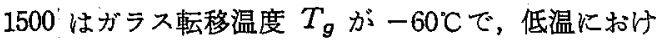
る結晶性はないといわれている。他方 BR 1441 は

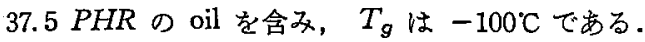
oil を含まない BR は低温結晶が $30 \%$ 程あり，その融

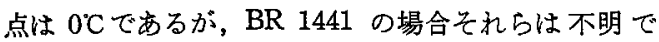
ある。加硫系はモノサルファイド結合をする $T T$ (Tetramethyl Thiuram Disulfide) 無硫黄加硫で, 加硫条件は $150^{\circ} \mathrm{C} て ゙ 60$ 分とした．配合は Table I に示 した，同 Table 中の網目密度は膨潤度測定から求めた。

Table I. Recipe.

\begin{tabular}{l|c|c|c|c|c}
\hline Sample & TT & ZnO & $\begin{array}{l}\text { Stearic } \\
\text { acid }\end{array}$ & PBNA & $\begin{array}{l}\text { Crosslink } \\
\text { density }\end{array}$ \\
\hline SBR-1500 & 3.0 & 5 & 2 & 1 & $1.19 \times 10^{4} \mathrm{~mole} / \mathrm{cc}$ \\
BR-1441 & 3.0 & 5 & 2 & 1 & $1.21 \times 10^{4} \mathrm{~mole} / \mathrm{cc}$ \\
\hline
\end{tabular}

\section{$2 \cdot 2$ 測定条件および方法}

厚さ $2 \mathrm{~mm}$ のシートから打ち拔いた, 外径 $20 \mathrm{~mm}$, 内径 $16 \mathrm{~mm}$ のリング状試片を用い,インストロン型 佰温槽付引張試験機で定速引張試験を行なった．引張

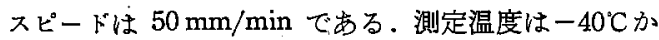
ら $120^{\circ} \mathrm{C}$ の間の 7 点を選んた゚。室温以上では予熱時間 15分, 室温以下では，ドライアイス中に45分放置後, 測定温度に15分置いてから測定した。リング状試片を 用いたため，伸びと張力の算出は次の関係から計算し た.すなわち、チャックの移動距離を $\Delta l$, リングの半 径を $r$, 検出張力を $F$, 試片の断面積を $S$ とすると, 伸度 $\alpha$, 初期断面積当たりの張力 $f$ は $\alpha=\Delta l / \pi r+1, f$ $=F / 2 S$ となる。

\section{3 結果および考察}

\section{$3 \cdot 1$ 張力一伸度測定曲線と理論曲線との比較}

3・1・1 Mooney-Rivlin 式との比較 よく知ら れているよ 5 に, Mooney-Rivlinの式は次式で与えら れる。

$$
f=\left(2 C_{1}+\frac{2 C_{2}}{\alpha}\right)\left(\alpha-\frac{1}{\alpha^{2}}\right)
$$

ここで $f$ は初期単位断面積当たりの張力， $\alpha$ は伸度 $C_{1}, C_{2}$ は定数である.この式と測定デ一タとの比較 学Fig. 1，2示した。これらの図では $f /\left(\alpha-1 / \alpha^{2}\right)$ を 1/a に対してプロットした）データが(2)式の関係 に従うとすれば，この関係は直線になるはずである。 $\mathrm{SBR}, \mathrm{BR}$ ともに中高温領域 $\left(30^{\circ} \sim 120^{\circ} \mathrm{C}\right)$ では, 伸 度の大きいところで逆 $\mathrm{S}$ 字状に立ら上がる以前に切断 するから，その温度領域のデータは(2)式で記述できる ようである(Fig. 1(a)，Fig. 2(a))。しかし，常温より
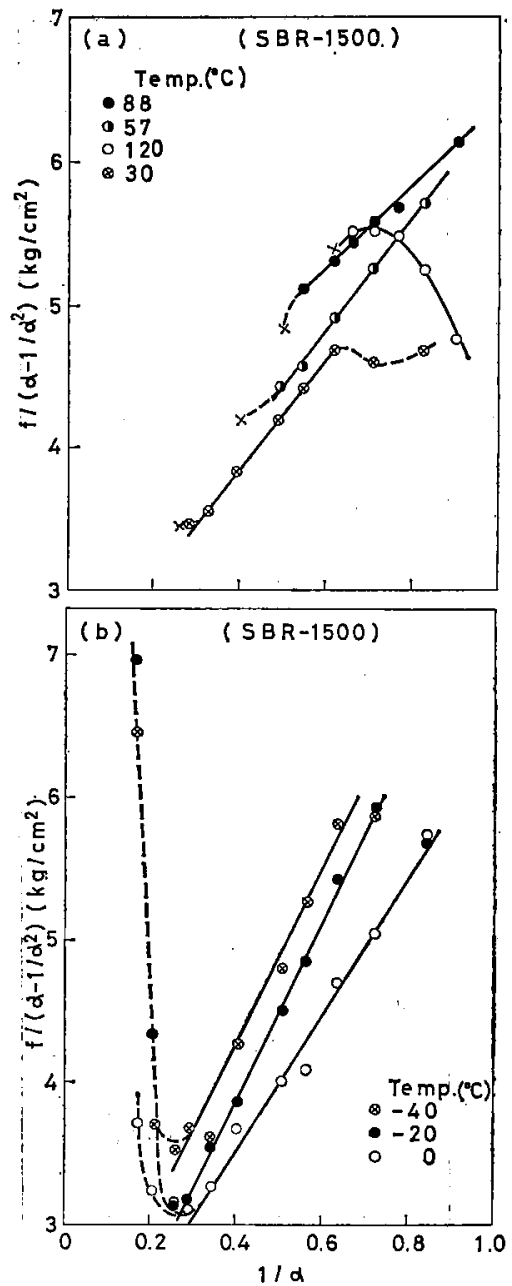

Fig. 1. Stress-strain relations of SBR vulcanizate by means of Mooney-Rivlin plots.

いくぶん低温の温度領域 $\left(0^{\circ} \sim-40^{\circ} \mathrm{C}\right)$ では, SBR, BR とも逆 $\mathrm{S}$ 字状の張力一伸度関係を示す. それらのデー

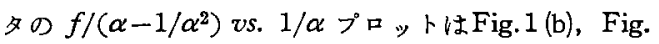
2 (b)にみられるよ5に，極小值をるつ. MooneyRivlin 式では同図の直線部分の伸度領域しか測定デー タを記述できない。

1/ $\alpha$ の大きなころで $f /\left(\alpha-1 / \alpha^{2}\right)$ の值が落ちて いるあのがあるが，それは初期緩和のためと思われる。

$3 \cdot 1 \cdot 2$ (1)式との比較 測定と(1)式を比較するた め, (1)式を次の形に変形した。

$$
\frac{f}{\left(\alpha-1 / \alpha^{2}\right)}=A+\left(1 / \alpha+D \alpha^{2}\right) B, D \equiv C / B
$$

この式で $f /\left(\alpha-1 / \alpha^{2}\right)$ の值は， $C>0$ ならば $1 / \alpha=$ $(2 C / B)^{1 / 3}$ で極小值をとる.その極小値のときの $1 / \alpha$ の值を $(1 / \alpha)_{\min }$ とすると $D=(1 / \alpha)^{3}{ }_{\min } / 2$ の関係 が得られる。そこで，まず測定值 $f /\left(\alpha-1 / \alpha^{2}\right)$ を 

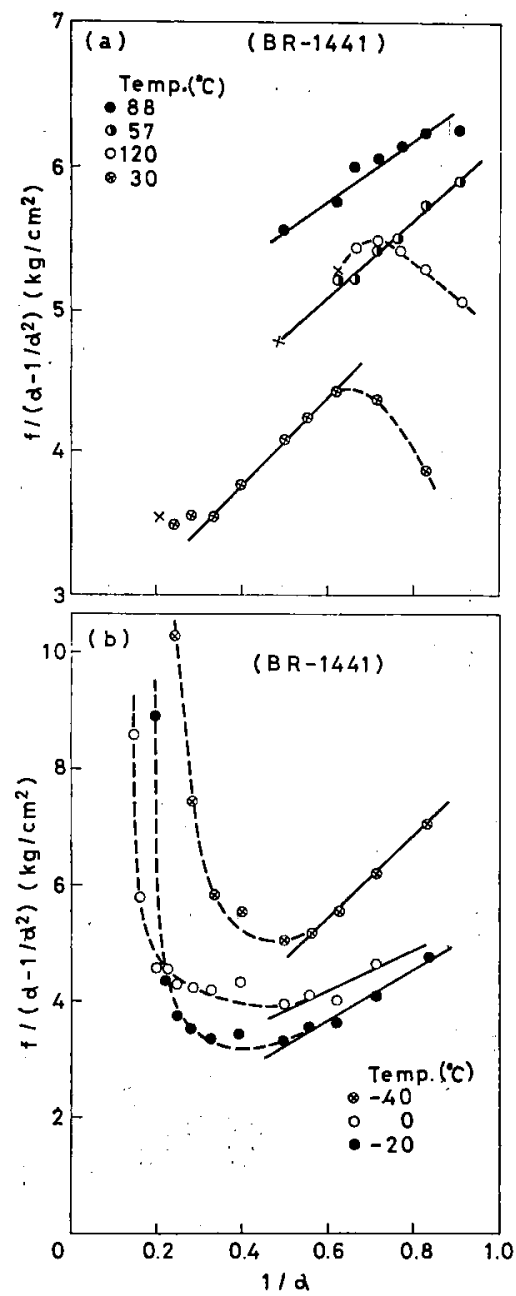

Fig. 2. Stress-strain relations of BR vulcanizate by means of Mooney-Rivlin plots.

$1 / \alpha$ U対してプロットし $(1 / \alpha)_{\min }$ の值を求め $D$ を計 算し，それを用いて $f /\left(\alpha-1 / \alpha^{2}\right)$ を $\left(1 / \alpha+D \alpha^{2}\right) に$ 対してプロットした．測定が(1)式に従うとすれば、こ のプロットで直線関係が得られるはずである。そして その直線のこう配は定数 $B$ を与兄, 切片は定数 $A$ 走与 える. 定数 $C$ は $D=C / B$ の関保から定まる. (1)式の $C$ を0とすると，(1)式は Mooney-Rivlin 式と同形にな るから，先の Mooney-Rivlin 式との比較で検討した 結果より，30C以上のデータは(1)式で記述できるとい える. 30 C以下の低温頜域のデータについては(1)式と 比較してその結果をFig. 3 亿示した. SBR, BR とも $\alpha=4 \sim 4.5$ 位まで注棌(1)式の関倸がなりたっているよ うである.このことは, さきの Mooney-Rivlin プロ ットでみると，(1)式は $1 / \alpha$ の小さい領域での極小值 から立ち上がっている部分の 1 部まで記述できること を示している. Mooney-Rivlin 式は，この温度領域
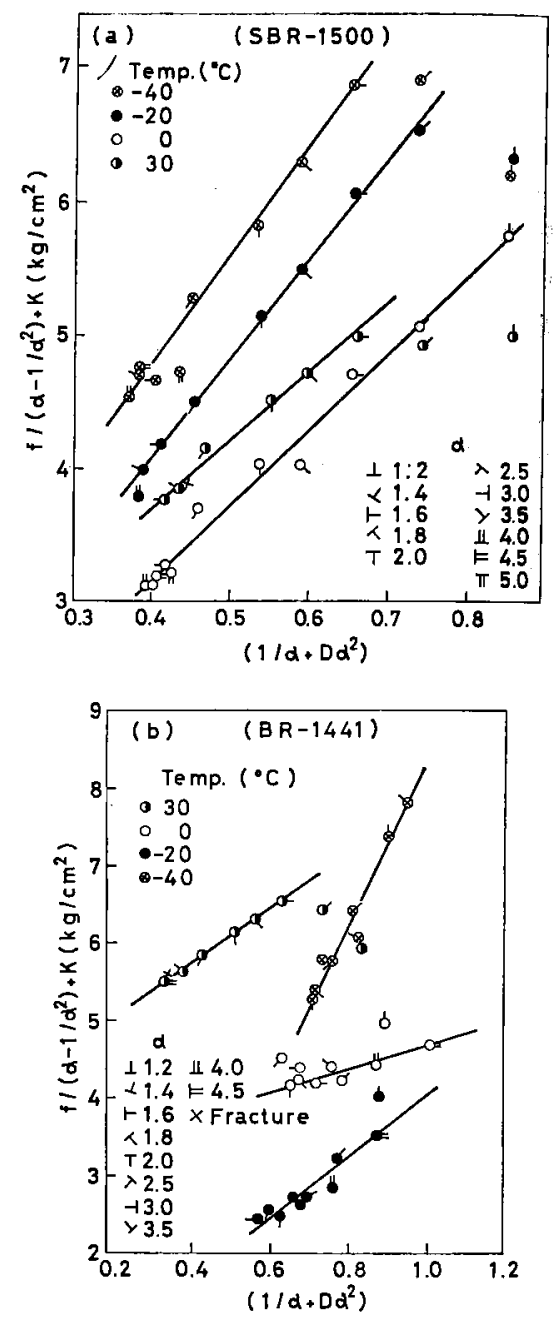

Fig. 3. Stress-strain data for SBR and BR plotted for comparison with straight lines predicted by Eq. (1).

のデータに対して $\alpha=3$ くらいまで合うにすぎない，

\section{$3 \cdot 2 \mathrm{~A}, \mathrm{~B}, \mathrm{C}$ の温度依存性}

Fig. 3 の直線のこう配と切片から求めた定数 $A, B$, Cの温度体存性をFig. 4 に示した，高温でAは温度 $T$ に比例し， $B, C$ 温度上昇とともに減少している. 全般に $C$ の值は小さく $A, B$ の值の百分の一の order である. $A$ は注ぼ Mooney-Rivlin 式に打ける 非平衡状態の $2 C_{1}$ に，同しく $B ， C$ はあわせてだいた い非平衡の $2 C_{2}$ に対応するとみなせる．Aが温度とと む淔線的に增加していることから，A項か沈力のエ ントロピー成分であることが予想される。あた $B ， C$ は温度上昇とともに0に向かって減少していることか ら, 内部エネルギの効果の方が大きいと推定される， $B, C$ はこの実験の温度領域では 0 にはならないが, Cは60С以上で0Kなる.他のゴムでは，平衡データ 

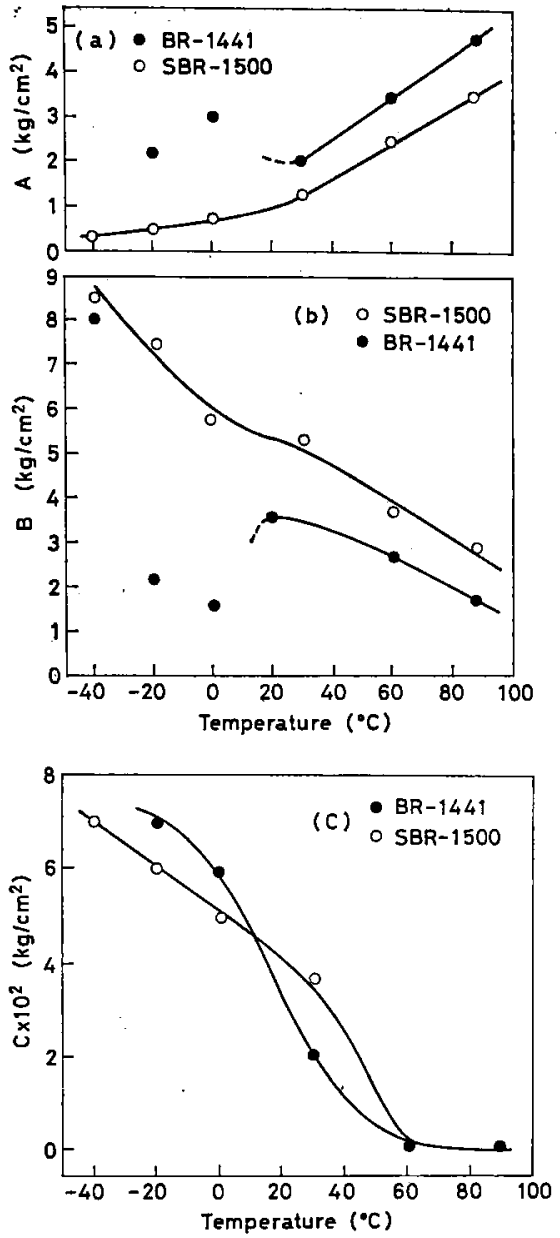

Fig. 4. Temperature dependences of the coefficients $A, B$ and $C$.

の $2 C_{2}$ が0になるものも多い. $\mathrm{B} \mathrm{R}$ のデータでは $A$, $B$ のバラッキがみられる。これは低温結晶や，伸長に よる結晶化のためとも考えられる。

\section{$3 \cdot 3$ 破壊強度と $\mathrm{C}$ 項の関係}

(1)式が S-S 曲線の立ち上がり始めの部分までかな り近似できるのは $C \alpha^{2}$ 項による。 ゆ壳にCの值と破 壊強度 $\sigma_{b}$ とは増加関数のような相関があるように予 想される。そこで $\sigma_{b}$ とCの関係をプロットしてみた が，果してFig. 5 にみられるよ5に $\sigma_{b}$ はCの増加と とすに増加していることが確められた。ゴムを強くす るめやすの1つとして, 常温, 中高温でCが大きいよ うな原料や配合を選ぶ研究も実用上重要であ万5.

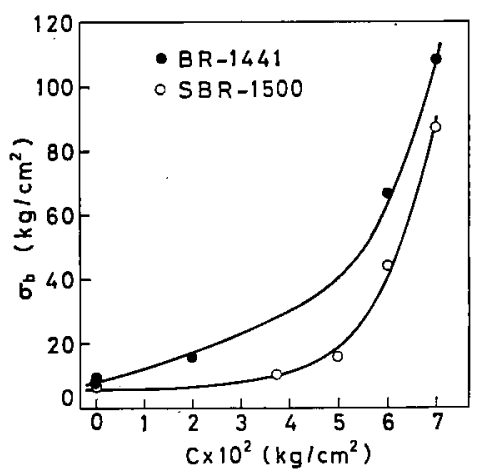

Fig. 5. Relation between the value of $C$ and tensile strength.

$$
4 \text { あとがき }
$$

ここで使用したデータは，特にこの研究のために測 定されたるのではなく，手持らのデータを用いたため， 平衡状態での S-S 関係を得るよらな配慮は特にされ てい寸゙またかなり粗いるのである。したがってこれ は予備的な研究にすぎない。

（昭和44年10月21日 第17回レオロジー討論会にて評演）

参考 献

1) Treloar, L.R.G., "The Physics of Rubber Elasticity " (1949) Oxford

2) Sato, Y., J. Soc. Material Sci. Japan, 19, 272 (1970). 